final decision until the specimens can be compared with Comstock's types.

Quite often, instead of midges, chalcids would appear in the cages. Mr. Crawford of the Bureau of Entomology pronounces these insects to be of a new species, belonging in a new genus, and he proposes to describe the species as Zatropis catalpa. Whether the chalcids were present in the catalpæ shoots as parasites on the midge larvæ, or whether, like the wheat-joint worm and a few other members of the family, they are primarily injurious to vegetation, I cannot at present state. It is not impossible that the midges work on the tender leaves at the terminal end of the twigs, and that the chalcids insert their eggs in the soft wood lower down. Several specimens of the chalcid were obtained this season, all issuing between the middle of July and the middle of August. The three midges obtained emerged August 7 , August 8 and September 3, respectively.

\title{
THE CALIFORNIA LIFE HISTORY OF THE GRAPE LEAF-HOPPER
}

Typhlocyba comes Say

By H. J. QuaYle, Berkeley, Cal.

Climate is a well-known factor in influencing the life history of insects, and so in California most, if not all, of our insects of economic importance have some points in their life-history that differ from those of the same species in the eastern states. Usually this difference is in the number of broods or length of the period of development, and less often a distinct variance in habits.

The grape leaf-hopper in California over-winters as an adult insect, feeding on a wide range of food plants during the warmer days; or remaining more or less dormant in bunches of leaves in the vineyard or low down in the dense vegetation of the bordering roadsides and fences during the cold or wet weather. As soon as the foliage appears on the vine in the spring they leave their varied winter food-plants and attack the grape exclusively. After feeding for about three weeks on the vine, pairing begins and eggs will be deposited one week later. This will be about May 1st in the lower Sacramento and San Joaquin valleys. Records were kept on twenty eggs from different hoppers and they required from seventeen to twenty days for incubation. Nymphs hatching from these eggs require on an average eighteen days to go through their five nymphal stages. The duration of each of the stages, summarized from observations on about fifty hoppers, is as 


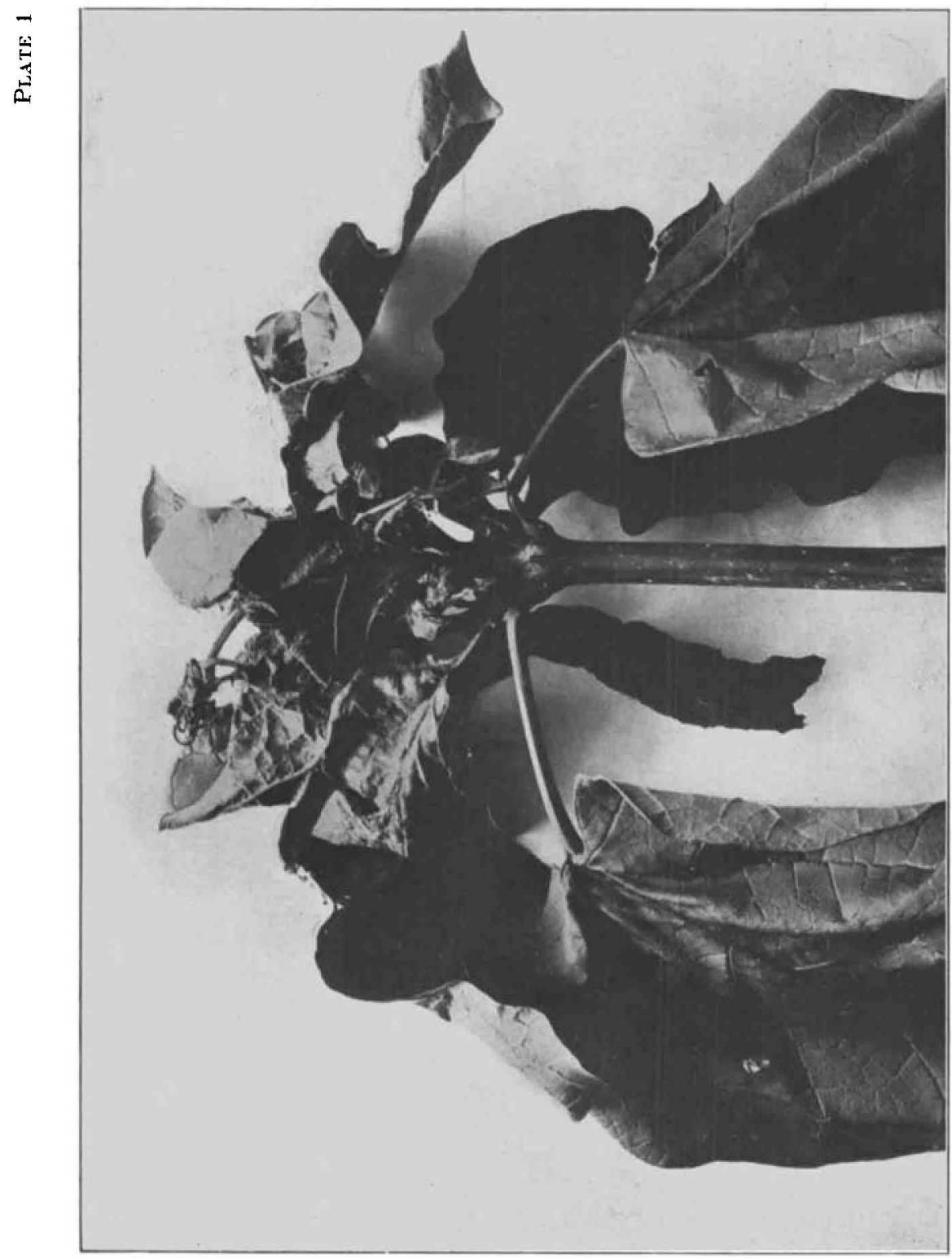

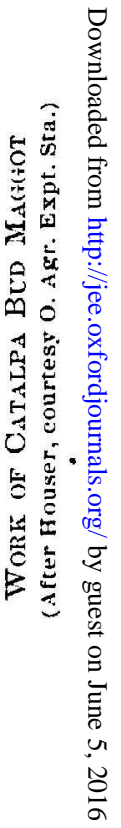




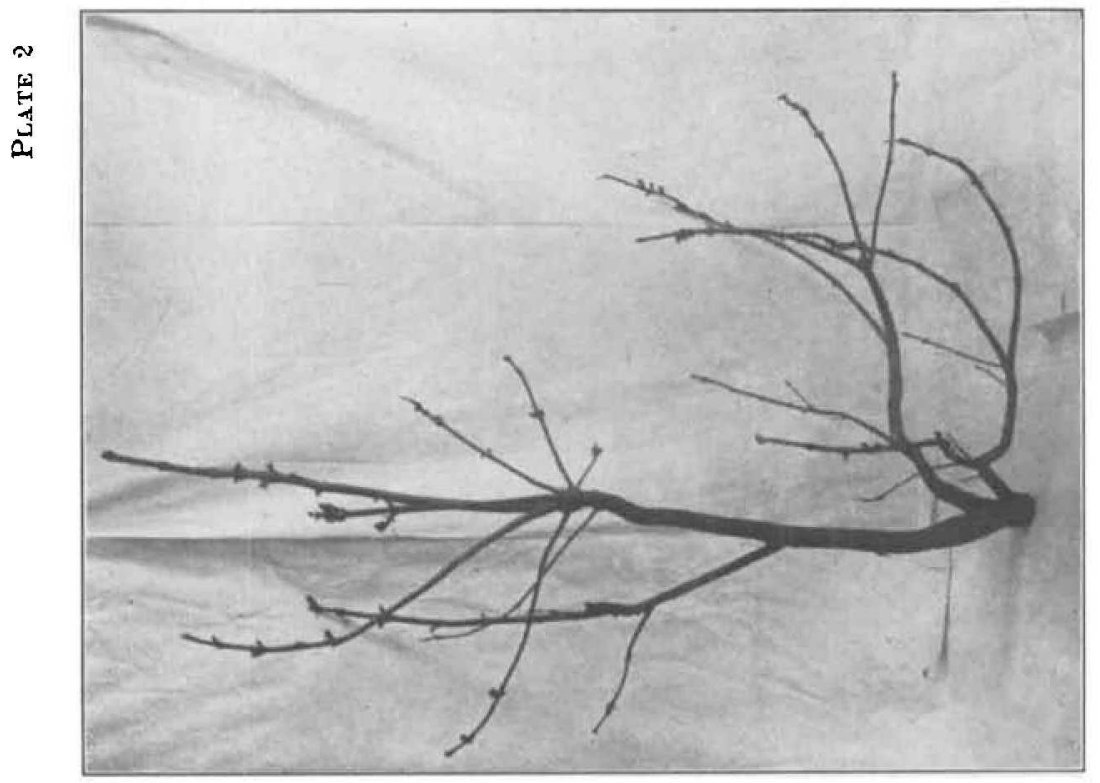

$n$



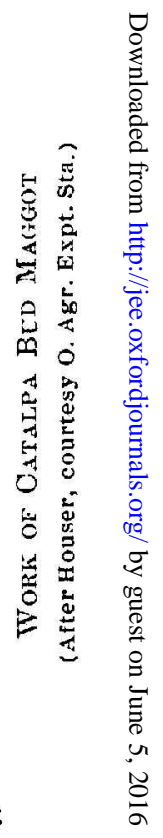


follows: First stage, four days; second stage, two days; third stage, three days; fourth stage, four days, and fifth stage, five days. Total, eighteen days.

The same insect in New York, as has been determined by Slingerland, requires from thirty to thirty-three days for its nymphal development. There is then a difference of two weeks in the time of development of the grape leaf-hopper in New York and that of the same insect in California. This difference is generally attributed to climate, although there is little difference between the climate of upper San Joaquin Valley in California in June and July and that of New York in the same months.

During the last week in June the hoppers, arising from the eggs of the over-wintering hoppers laid in May, begin egg laying, which is continued throngh July and a part of August. The incubation period was noted for a hundred or more eggs and they all hatched in from eight to twelve days. This is a shorter period than was required for the eggs to hatch in May from the over-wintering insects, and may be due to the difference in temperature.

A number of hoppers were confined in individual breeding cages on the leaves of the grape, and the number of eggs laid varied from forty to one hundred and twenty-one, distributed over a period of from three to seven weeks.

Hoppers hatching from these eggs remain on the vine until the leaves fall, when they attack their winter food plants, which include a large number of plants that may be growing in the vineyard or vicinity. These attack the vine in the spring, begin egg laying in May, and die off in July, making the length of the life cycle approximately one year. The spring brood hatching in May lives until about August or September, thus completing the life cycle in three or four months. There are thus two broods of the grape leaf-hopper in California, and, at least during the past year, there was no indication of a third brood.

\section{NOTES OF THE SEASON}

\section{By H. A. Gossarb, Wooster, Ohio}

The season opened with a noteworthy weather condition that seems to have had a perceptible effect on the development of San Jose scale. March 19 the mereury rose to $68^{\circ}$ at Wooster, and the following maximum temperatures were recorded at this place during the next two weeks : 